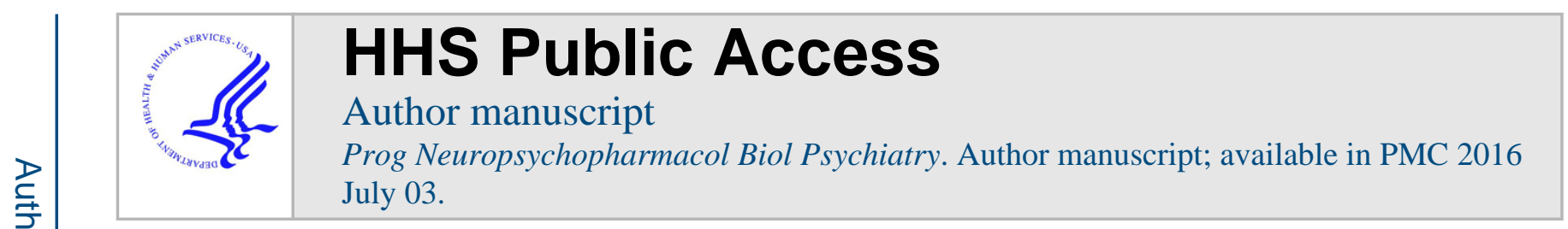

Published in final edited form as:

Prog Neuropsychopharmacol Biol Psychiatry. 2015 July 3; 60: 66-76. doi:10.1016/j.pnpbp.2015.02.012.

\title{
Perspectives on the $\mathrm{mGluR2/3}$ agonists as a therapeutic target for schizophrenia: still promising or a dead end?
}

\author{
Meng-Lin $\mathrm{Li}^{1,2}$, Xi-Quan $\mathrm{Hu}^{2}$, Feng $\mathrm{Li}^{3}$, and Wen-Jun Gao ${ }^{1,}$ \\ ${ }^{1}$ Drexel University College of Medicine, Philadelphia, PA, USA \\ ${ }^{2}$ Department of Rehabilitation, Third Affiliated Hospital of Sun Yat-Sen University, Guangzhou, \\ China \\ ${ }^{3}$ Department of Neurobiology and Anatomy, Zhongshan School of Medicine, Sun Yat-Sen \\ University, Guangzhou, China
}

\section{Abstract}

Group II metabotropic glutamate receptor (mGluR2/3) agonists once showed promise as nondopaminergic antipsychotic drugs because of their efficacy in alleviating symptoms of schizophrenia (SZ) in both animal models and human patients. However, the recent failure of Phase III clinical trials dealt a huge blow to the scientific community and the aftershock of the setback in mGluR $2 / 3$ research can be felt everywhere from grant support and laboratory studies to paper publication. An immediate question raised is whether mGluR2/3 is still a promising therapeutic target for schizophrenia. Answering this question is not easy, but apparently a new strategy is needed. This article provides a focused review of literature on the study of mGluR2/3 agonists, especially on mGluR2/3 agonists' mechanism of action and efficacy in both normal conditions and animal models of SZ, as well as clinical studies in human patients with the disease. We argue that the cellular and molecular actions of mGluR2/3 agonists, the distinct roles between mGluR2 and mGluR3, as well as their effects on different stages of the disease and different subpopulations of patients, remain incompletely studied. Until the mechanisms associated with mGluR2/3 are clearly elucidated and all treatment options are tested, it would be a great mistake to terminate the study of mGluR2/3 as a therapeutic target for schizophrenia. This review will thus shed light on the comprehensive features of the translational potential mGluR2/3 agonists as well as the need for further research into the more selective activation of mGluR2.

(C) 2015 Published by Elsevier Inc.

*Correspondence: Wen-Jun Gao, Ph.D., Department of Neurobiology and Anatomy, Drexel University College of Medicine, 2900 Queen Lane, Philadelphia, PA 19129, Phone: (215) 991-8907, Fax: (215) 843-9802, wgao@drexelmed.edu.

Conflict of interest

The authors claim no financial conflicts of interest.

Publisher's Disclaimer: This is a PDF file of an unedited manuscript that has been accepted for publication. As a service to our customers we are providing this early version of the manuscript. The manuscript will undergo copyediting, typesetting, and review of the resulting proof before it is published in its final citable form. Please note that during the production process errors may be discovered which could affect the content, and all legal disclaimers that apply to the journal pertain. 


\section{Keywords}

Metabotropic glutamate receptors; mGluR2/3 agonists; NMDA receptor hypofunction; antipsychotics; schizophrenia

\section{Introduction}

Schizophrenia (SZ) is a chronic mental disorder with an incidence of about $0.3-1.0 \%$ in the human population (Howes and Kapur, 2009). Although the etiology of the disease remains unclear, SZ is believed to be a multifactorial disease, including genetics, environmental, psychological, and social factors. Symptoms of SZ include positive symptoms, negative symptoms, and cognitive deficits. The cognitive impairment is considered the most complicated dysfunction of SZ, and these deficits are present prior to the onset of psychosis and persist through development. There are no prominent molecular and cellular abnormalities, making diagnosis difficult, and development of successful therapeutics extremely challenging. The current treatment of SZ consists of primarily dopaminergic antipsychotic medications, which antagonize D2 receptors, combined with vocational and psychological counseling. These treatments, however, are only effective in positive symptoms, and the efficacy in negative and cognitive symptoms are very limited (Miyamoto et al., 2005). Recent progress has suggested a clinical potential in utilizing other pharmacological agents (Chaki et al., 2013, Durand et al., 2013, Niswender and Conn, 2010). Here we will focus on the studies of $m G l u R 2 / 3$ agonists as a potential antipsychotic drug for the treatment of SZ.

Based on the sequence homology, second messenger coupling, and pharmacological characteristics, mGluRs are classified into three major groups and eight subtypes: group I (mGluR1/5), group II (mGluR2/3), and group III (mGluR4/6/7/8) (Conn et al., 2009, Conn and Pin, 1997, Fell et al., 2012, Harrison et al., 2008, Mezler et al., 2010, Niswender and Conn, 2010, Schoepp et al., 1999).

The mGluR2/3 has long been linked to SZ (Moghaddam, 2004). Both type-2 and 3 metabotropic glutamate receptor gene (GRM 2 and 3) single nucleotide polymorphisms (SNPs) have been associated with cognitive performance and prefrontal cortex activity levels in SZ patients (Bishop et al., 2015, Chen et al., 2005, Egan et al., 2004, Harrison, Lyon, 2008, Joo et al., 2001, Kordi-Tamandani et al., 2013, Mossner et al., 2008). Administration of LY354740, a prototypical mixed mGlu2/mGlu3 agonist, effectively attenuated the disruptive effects of phencyclidine (PCP) on working memory, stereotypy, locomotion, and cortical glutamate efflux in the PCP model of SZ, at a dose that was without effects on spontaneous activity and corticolimbic dopamine neurotransmission (Moghaddam and Adams, 1998). LY354740 also reduced amphetamine (AMPH)-induced hyperlocomotion in rats (Cartmell et al., 1999). Subsequently, many other similar compounds have been developed, such as LY404039, LY404039's prodrug LY2140023, LY379268, etc. These drugs by activating mGluR2/3 offer promising therapeutic benefits to patients with SZ (Conn, Lindsley, 2009, Moghaddam, 2004, Moghaddam and Adams, 1998, Rotaru et al., 2011, Weinberger, 2007).

Prog Neuropsychopharmacol Biol Psychiatry. Author manuscript; available in PMC 2016 July 03. 
However, in 2012, mGluR2/3 agonist LY2140023 (pomaglumetad methionil) failed to meet the primary endpoint based on the positive and negative syndrome scale (PNASS) in Phase III clinical trials, questioning whether mGluR2/3 may be a therapeutic target for SZ. Despite this, we assert that with further research and new approaches, mGluR $2 / 3$ drugs may still be a viable clinical option. This review will focus on mGluR2/3 agonists' working mechanisms, the outcomes of in vivo animal studies and clinical trials, distinct functions of mGluR2 and mGluR3, the application status of newly selective mGluR2 agonists and positive allosteric modulators (PAM), as well as comparisons between mGluR2/3 agonists and current antipsychotics, in order to provide insights and future directions for research on mGluR2/3 agonists for SZ treatment.

\section{Working mechanisms of $m$ GluR2/3 agonists in the brain}

GABAergic interneurons in the central nervous system are activated by the axon collaterals of excitatory neurons and exert a powerful inhibitory feedback to these excitatory cells. Based on the NMDA hypofunction hypothesis, the hyperglutamatergic condition results from the decreased action of NMDA receptors on GABAergic neurons, which in turn reduces inhibitory control of excitatory pyramidal neurons, leading to increased glutamate release and excessive stimulation of glutamatergic (e.g., AMPA/KA) receptors. This eventually results in excitotoxic damage and cognitive impairment (Lindsley et al., 2006, Lisman et al., 2008, Nakazawa et al., 2012, Olney and Farber, 1995, Olney et al., 1999, Snyder and Gao, 2013). mGluR2/3 agonists are proposed to decrease presynaptic glutamate release on excitatory neurons (Figure 1), which in turn reverses the hyperglutamatergic condition, and thus alleviates symptoms in SZ patients.

This heuristic hypothesis is obviously appealing, but how do mGluR2/3 agonists achieve this sophisticated action in such a delicate and even cell-type specific manner? It is widely believed that stimulation of presynaptically-localized mGluR2/3 modulates glutamate release through activation of $\mathrm{G}_{\mathrm{ai} / \mathrm{o}}$ pathway, as shown in Figure 1. It begins with adenylate cyclase (AC) catalyzing the conversion of cytosolic adenosine triphosphate (ATP) to cyclicadenosine monophosphate (cAMP). In this pathway, activation of $\mathrm{G}_{\mathrm{ai} / \mathrm{o}}$ directly inhibits $A C$ and thus decreases the production of cAMP. The level of cAMP determines the activity of various ion channels as well as members of the serine/threonine-specific protein kinase A (PKA) family. Therefore, the activation of mGluR2/3 leads to decreased glutamate release presynaptically by inhibiting AC-cAMP-PKA pathway (Anwyl, 1999, Cartmell and Schoepp, 2000, Moghaddam, 2004, Schoepp, Jane, 1999).

However, mGluR2/3 agonists also enhance postsynaptic excitatory receptor function, including both AMPARs and NMDARs, by regulating several intracellular pathways, as exhibited in Figure 2. Treatment of PFC slices with APDC, a highly selective and potent mGluR2/3 agonist, significantly increases the protein kinase $\mathrm{C}$ (PKC) activity and PKCmediated phosphorylation of NMDA receptors (Tyszkiewicz et al., 2004). In addition, mGluR2/3 agonist LY379268 directly modulates NMDAR expression and function and reverses dizocilpine (MK-801)-induced NMDA dysfunction via activation of the Akt/ glycogen synthase kinase $3 \beta$ (GSK3 $\beta$ ) pathway postsynaptically (Xi et al., 2011). In cultured prefrontal cortical neurons, LY379268 also increases the surface expression and function of 
AMPA receptors through activating extracellular signal-regulated kinase1/2 (Erk1/2) and GSK3 $\beta$ signaling pathways (Wang et al., 2013). Moreover, activation of mGluR2/3 in the postsynaptic site can also inhibit AC-cAMP-PKA pathway, and thus indirectly activate Src signaling, resulting in an upregulation of NMDAR function (Trepanier et al., 2013). To elucidate the underlying mechanisms in this neuronal proccess, a recent study has identified several key molecules involved in the group II mGluR-induced potentiation of NMDAR exocytosis and function. Activation of mGluR2/3 by the agonist APDC increases Rab4 activity and the interaction between Rab4 and syntaxin 4, facilitating the formation of SNARE complex that is composed of SNAP-25, syntaxin 4 and vesicle-associated membrane protein (VAMP) at postsynaptic sites, which leads to the increased exocytosis of NMDARs (Cheng et al., 2013).

The postsynaptic effects of mGluR2/3 agonists on glutamatergic receptors however, are contradictory to the hypothesis of reversing hyperglutamatergic state via presynaptic action of reducing glutamate release. At this point, it remains unclear how to reconcile these seemingly discordant findings and determine what the net effects of mGluR $2 / 3$ activation are on brain function, particularly cognition and behavior. It appears that the presynaptic action is an immediate and direct effect of mGluR2/3 activation, whereas activation of mGluR2/3 in the postsynaptic site engages an indirect and slower effect on intracellular signaling pathways to modulate the glutamate receptors. It is possible that through presynaptically reduced glutamate release and postsynaptically enhanced glutamate receptor function, mGluR2/3 agonists are able to modulate synaptic transmission, and reset the balance of synaptic activity to a new "normal" condition, consequently alleviating the hyperglutamatergic condition in SZ individuals. Still, how exactly this paradoxical action of a presynaptic decrease of glutamate and postsynaptic increase of receptor function results in a net effect that could treat the disease remains to be explored.

Further, understanding mGluR2/3's interactions with dopaminergic, serotoninergic and GABAergic systems will allow for a better understanding of mGluR2/3 agonists' roles in brain function and behavior, as well as their potential for SZ treatment. Current studies have demonstrated that elevated dopamine function is associated with glutamatergic dysfunction in SZ (Pauli et al., 2013), and serotonin regulates both dopamine and glutamate neurotransmission in cortical and sub-cortical regions (de Bartolomeis et al., 2013). A fundamental question is whether activation of mGluR2/3 can directly affect dopamine D2 receptors to achieve the necessary antipsychotic action without targeting the glutamate system, as argued by Seeman et al. (Seeman et al., 2008, Seeman and Guan, 2009, Seeman and Guan, 2008). However, a recent study provides both in vitro and in vivo evidence for a lack of interaction with dopamine D2 receptors by the mGlu2/3 receptor agonists LY354740 and LY379268 (Fell et al., 2009). Interestingly, a direct 5-HT2AR-mGluR2 interaction between the receptor complex seems to be involved in the altered cortical processes of SZ, providing a promising target for the treatment of psychosis (Fribourg et al., 2011, GonzalezMaeso et al., 2008). Further, glutamate and GABA are the major excitatory and inhibitory neurotransmitters that are critical for normal neuronal signaling. Some crucial intracellular signaling pathways, such as the Akt/GSK-3 $\beta$ signaling pathway, which is closely relevant to the psychotic condition, has been reported to be significantly influenced by interactions of 
dopamine, serotonin, GABA and glutamate transmission (de Bartolomeis, Buonaguro, 2013, Li et al., 2011, Li and Gao, 2011, Li et al., 2012, Li et al., 2009, Xi, Li, 2011). As a result, it is important to take different systems' interactions into account when evaluating each drug's efficiency. It is possible and likely, during the progression of SZ, glutamatergic dysfunction presents first in the early stage with cognitive impairment, which in turn, affects the dopamine and serotonin system, as well as GABAergic inhibition in the later stages with negative symptoms and psychosis, as proposed by Howes and Kapur in the revised dopamine hypothesis (Howes and Kapur, 2009). Given this, patients' complete medication history should be considered when selecting research subjects for clinical trials or prescribing new medications.

\section{Differential role of $m$ GluR2 and mGluR3 in antipsychotic and neuroprotective actions}

Despite the joint action of mGluR2/3 agonists, there is evidence indicating that mGluR2 and mGluR3 may exhibit different actions in normal brain function and in the abnormal condition of SZ (Table 1). First, mGluR2 and mGluR3 show distinct regional distributions in the central nervous system (Marek, 2010). Using a tritiated LY459477, a selective and structurally novel mGlu2/3 receptor agonist, the distribution of mGluR2 and mGluR3 was studied in transgenic mice lacking either mGluR2, mGluR3, or both receptors. The data show that brain regions enriched in mGluR2 include the medial prefrontal cortex, selected hippocampal regions such as CA1 and dental gyrus, the medial mammillary nucleus, the medial habenula, and the cerebellar granular cell layer, whereas regions enriched in mGluR3 are the dorsolateral entorhinal cortex, the hippocampal CA1 field, the piriform cortex, the substantia nigra, the thalamic reticular nucleus, and primary sensory thalamic nuclei (Wright et al., 2013).

Second, mGluR2 and mGluR3 are expressed in different cells. While both mGluR2 and mGluR3 are localized to neurons, only mGluR3 is expressed in astrocytes (Petralia et al., 1996, Tamaru et al., 2001). These studies also suggest that populations of mGluR2 and mGluR3 receptors are localized differentially in synapses, i.e. those in and near the presynaptic and postsynaptic membranes and in glial wrappings of synapses, in several regions of the brain. Specifically, mGluR2 is expressed in both pre- and postsynaptic elements, having no close association with synapses, whereas the vast majority of mGluR3 in presynaptic elements is not closely associated with glutamate and GABA release sites in the striatum and thalamus, respectively. However, in the spines of the dentate granule cells, the highest receptor density was found in perisynaptic sites. These results indicate that the localization of mGluR3 in the postsynaptic elements has a unique functional role in glutamatergic neurotransmission (Petralia, Wang, 1996, Tamaru, Nomura, 2001). Thus, mGluR2 and mGluR3 receptors are found in various combinations of presynaptic, postsynaptic and glia localizations that may reflect differential modulation of synaptic transmission.

Third, evidence suggests that mGluR2 plays an important role in mediating antipsychotic activity in SZ (Fell et al., 2008, Woolley et al., 2008), while mGluR3 is crucial in exerting neuroprotective effects (Durand, Carniglia, 2013). Using mGluR2- and mGluR3-deficient

Prog Neuropsychopharmacol Biol Psychiatry. Author manuscript; available in PMC 2016 July 03. 
mice, two independent studies investigated the relative contribution of mGluR2 and mGluR3 in mediating the antipsychotic profile of LY404039, a potent mGluR2/3 agonist, in PCP and AMPH models of psychosis. The antipsychotic-like effects of LY404039 (10 $\mathrm{mg} / \mathrm{kg}$ i.p.) on PCP and AMPH-evoked behavioral activation (i.e., increased ambulation, increased distance, and reduced time spent at rest) only exists in mGluR3-deficient mice but not in mGluR2- or mGluR2/3-deficient mice, indicating that activation of mGlu2, but not mGlu3 receptors, is responsible for the antipsychotic-like effect of LY404039 (Fell, Svensson, 2008, Woolley, Pemberton, 2008). In contrast, in cultured astrocytes, which lack mGluR2 subunits, mGluR2/3 agonist LY379268 exhibited no neuroprotective actions, suggesting that the neuroprotective effect of mGlu2/3 agonists is mostly derived from activation of mGluR3 in astrocytes (Corti et al., 2007). Apparently, mGluR3's antipsychotic effects remain to be characterized, but its specific role in neuroprotection through promoting the release of neurotrophic factors in astrocytes (Bruno et al., 1998, Bruno et al., 2001, Bruno et al., 1997) and ameliorating both the induction and progression of neuronal degeneration (Nicoletti et al., 1996) have been well characterized (Durand, Carniglia, 2013).

\section{In vivo studies of mGluR2/3 agonists in animal models of $S Z$}

There are different types of animal models for SZ, including pharmacological, developmental (e.g. methylazoxymethanol acetate) and genetic models (e.g. DISC1) (Carpenter and Koenig, 2008). However, studies of mGluR2/3 agonists' effects on developmental and genetic SZ models are severely limited, and to our knowledge, there is no available literature exploring this important research question. One model that has been used extensively is the AMPH-induced SZ-like model (Table 2). AMPH works by increasing dopaminergic and noradrenergic activity in mesolimbic brain regions and produces acute SZ-like psychotic symptoms, usually with the presentation of hyperlocomotion (Auclair et al., 2002). With treatment of $10 \mathrm{mg} / \mathrm{kg} \mathrm{LY404039,} \mathrm{AMPH-}$ induced increases in ambulation and travel distance were reversed (Fell, Svensson, 2008). Other mGluR2/3 agonists such as LY354740 and LY379268 were found to have similar effects in regulating AMPH-induced psychosis and certain behavioral effects as LY404039 (Cartmell, Monn, 1999, Cartmell et al., 2000b, Galici et al., 2005, Woolley, Pemberton, 2008).

Another commonly used pharmacological model targets at the glutamate system, with NMDAR antagonists like PCP, ketamine and MK-801. In the PCP model, mGluR2/3 agonists (e.g., LY379268, LY354740, LY544344) were reported to effectively reverse certain behavioral phenotypes such as locomotor activity and prepulse inhibition (Cartmell et al., 2000a, Profaci et al., 2011, Rorick-Kehn et al., 2006, Swanson and Schoepp, 2002). LY379268 also resulted in a significant reduction in ketamine-induced hyperactivity (Imre et al., 2006, Lorrain et al., 2003b) and MK-801-induced hyperlocomotion (Chartoff et al., 2005, Xi, Li, 2011). However, when Cartmell et al. tested LY354740 and LY379268's effects on both PCP- and AMPH-induced SZ animal models, they found that administration of either LY354740 or LY379268 led to a marked reduction in PCP-evoked behavioral changes but had minimal effects on AMPH-evoked hyperlocomotion. This demonstrates mGluR2/3 agonists' specificity in targeting the glutamate system and the absence of effects on the dopaminergic signaling (Cartmell, Monn, 1999). 
An intriguing unanswered question concerns the effects of mGluR2/3 agonists on cognition and negative symptoms. Previous studies on the effects of mGluR2/3 stimulation on cognitive function produced conflicting results. Recent studies indicated that mGluR2/3 agonist LY379268 is effective in reversing post-weaning social isolation-induced recognition memory deficits (Jones et al., 2011) and in correcting a SZ-like phenotype induced by prenatal stress (Matrisciano et al., 2012). Selective mGluR2-PAM LY487379 also promotes cognitive flexibility and inhibitory behavioral control (Nikiforuk et al., 2010) and facilitates responses to sensory stimulation (Copeland et al., 2012) and social discrimination in rats that have been administered PCP (Harich et al., 2007). However, Schlumberger et al. reported that mGluR2/3 agonist LY354740 (3-10 mg/kg) did not modify PCP-induced working memory deficits assessed in a spontaneous alternation task and had no effect on PCP-evoked amnesia in the passive avoidance test (Schlumberger et al., 2009).

$\mathrm{SZ}$ is a neurodevelopmental disorder, and a failure to correct the synaptic disruption with treatment immediately following symptom onset would miss a critical treatment or prevention window for SZ. Because NMDAR dysfunction may occur during the early stage of the disease, early treatment would possibly be more effective. Indeed, targeting mGluRs in 1-month-old young mice is efficacious in reversing fragile X syndrome (Michalon et al., 2012), and cognitive training in adolescence prevents adult deficits in a neonatal ventral hippocampal lesion model of SZ (Lee et al., 2012). Therefore, it is critical to address the important concept of whether early-stage (juvenile period) treatment is able to reverse or prevent the progression of SZ, especially for cognitive deficits. Additionally, studies on mGluR2/3 agonist's dose-dependent effects and function under both normal and disease conditions are still limited. Galici et al. reported that LY379268 induced dose-dependent reductions in PCP- and AMPH-induced hyperlocomotor activity, but chronic treatment with LY379268 failed to replicate this effect (Galici, Echemendia, 2005). Given that drugs utilized in clinical populations are primarily administered chronically, an important question raised is whether the acute effects reported in most of the animal studies can be used as a reliable indicator for potential clinical efficacy and also whether chronic treatment with mGluR2/3 agonists will result in issues with tolerance. Finally, although mGluR2/3 agonists reversed certain cognitive deficits induced by NMDAR blockade (Moghaddam and Adams, 1998, Nikiforuk, Popik, 2010), in normal animals these agents had either no effects or even impaired cognition (Aultman and Moghaddam, 2001, Higgins et al., 2004, Schlumberger, Schafer, 2009). These findings are consistent with the hypothesis that the utility of mGluR2/3 agonists on cognitive function may be limited to conditions associated with NMDAR dysfunction or the disease state (Nikiforuk, Popik, 2010). All of these questions require more experiments to determine the most effective therapeutic window of mGluR2/3 agonists during different developmental periods, disease stages, or other conditions.

\section{The rise and fall of mGluR2/3 agonists in clinical trials for treatment of}

\section{SZ}

In an early clinical attempt, Patil et al. in Eli Lilly compared the mGluR2/3 agonist LY2140023 with olanzapine, an atypical antipsychotic, for treatment of SZ with bipolar 
disorder as an active control in a small population of patients in a randomized, double-blind, placebo-controlled study. This first Phase II clinical trial was an immediate success and promising. Patients with $40 \mathrm{mg}$ LY2140023 administered twice daily showed significant improvements in both positive and negative symptoms, but not in cognitive symptoms compared to the placebo (Patil et al., 2007) (Table 2).

However, in August 2012, Eli Lilly and Company suddenly announced their decision to stop Phase III development as their more complete Phase III clinical trial of mGluR2/3 agonist LY2140023 failed to meet its primary endpoint based on the unaltered PANSS scale (Adams et al., 2013, Adams et al., 2014). The cause of failure was multifaceted. One possibility could be that the patients used in the study may not respond to glutamate-based treatment due to their previous treatment history. It is likely that patients in the trial may have had prior exposure to other antipsychotics that block either $\mathrm{D} 2$ receptors, $5-\mathrm{HT}_{2 \mathrm{~A}}$ receptors, or both. Moreover, those patients with a history of a hyperdopaminergic condition will have more influential reactions to the drugs targeting dopaminergic receptors rather than glutamatergic receptors (Howes and Kapur, 2014). In fact, no significant difference in total mGluR2/3 density was identified in the prefrontal cortex (Frank et al., 2011, Ghose et al., 2009) and anterior cingulate cortex (Matosin et al., 2014) in SZ patients compared with healthy controls, although there was a negative correlation between mGluR2/3 density and age (Frank, Newell, 2011). It is therefore likely that mGluR2/3 alteration or glutamatergic dysfunction only occurs in the early stage of the disease. Another possibility could be that researchers choose to measure the PANSS instead of a cognitive-based endpoint. As Downing et al. mentioned, LY2140023 did not show significant improvement compared to placebo on PANSS total scores in SZ patients (Downing et al., 2014). However, Krystal et al. demonstrated that LY354740 produced a significant dose-related improvement in working memory in healthy human subjects who had been administered ketamine (Krystal et al., 2005). Although these results were contradictory to what Patil et al. reported (Patil, Zhang, 2007), a clinical trial evaluating cognitive improvement is definitely warranted, especially for those patients not responsive to dopaminergic antipsychotics. Therefore, more attention should be given to patient inclusion criteria and in understanding mGluR2/3 agonists' distinct effects on positive, negative and cognitive symptoms.

\section{Overview of more selective mGluR2/3 agonists: potentials of compounds as mGluR2 agonist/mGluR3 antagonist, mGluR2 positive allosteric modulator (PAM), and selective mGluR2 agonist}

As discussed above, mGluR2 and mGluR3 may play a different role in regulating neuronal and synaptic function. Therefore, it has been hypothesized that a more selective and potent mGluR2 agonist may exert a more specific antipsychotic action. Although the discovery of selective agonists of mGluR2 is a challenge, there have been recent advances in developing the highly selective mGluR2 agonist/mGluR3 antagonist LY395756 and positive allosteric modulators (PAMs) such as LY487379, JNJ-42153605, JNJ-40068782, and biphenylindanone A (BINA) (Dhanya et al., 2011, Niswender and Conn, 2010). 
When comparing mGluR2/3 agonist LY379268 with mGluR2 PAM LY487379 in the AMPH- and PCP-induced SZ model, unlike LY379268, LY487379 could reverse AMPHinduced disruption of prepulse inhibition (PPI) of the acoustic startle reflex, indicating a potential role in cognitive fragmentation (AMPH- and PCP-induced hyperlocomotion were unaffected) (Galici, Echemendia, 2005). With stronger metabolic stability, another PAM, JNJ-42153605 effectively reversed PCP-induced hyperlocomotion (Cid et al., 2012). In addition, it has been reported that JNJ-40068782 was able to potentiate the binding of mGluR2/3 agonists (Lavreysen et al., 2013). However, one of the most important obstacles in the development of a mGluR2 PAM for potential clinical use is that most of the compounds, such as BINA, are not water soluble, directly limiting their applicability in animal models to assess effects on mitigating behavioral deficits.

A promising mGluR2 PAM that may shed light onto PAMs' therapeutic value in clinical populations is ADX71149 (Addex Company). Recently, Addex announced in a press release that ADX71149 has passed a Phase IIa clinical study that demonstrated that ADX71149 not only met the primary criterion of safety and tolerability, but also affected patients with negative symptoms (Hopkins, 2013). Although promising results of ADX71149 in clinical studies have been demonstrated, its Phase III clinical trial results have not been released. Research about PAMs remains insufficient, and more laboratory and clinical researches are needed to obtain a better understanding of PAMs' comprehensive properties. Further clinical investigations comparing mGluR2/3 agonists and mGluR2 PAMs, as well as a selective agonist of mGluR2, are still necessary.

\section{Advantages and disadvantages in application of mGluR2/3 agonists}

Compared to other typical and atypical antipsychotic drugs, mGluR2/3 agonists have many advantages that warrant further investigation. The mechanisms of mGluR2/3 agonists and most of the current antipsychotic medications are distinct. While typical (e.g. haloperidol) and atypical (e.g. clozapine and olanzapine) antipsychotics both target the dopamine system, atypical antipsychotics exert effects on the serotonin system as well. Typical antipsychotics are associated with a higher rate of extrapyramidal symptoms (EPS) which can be explained by specific inhibition of dopamine receptors (Miyamoto, Duncan, 2005, Tamminga, 1997), whereas atypical antipsychotics display fewer EPS and more weight gain, diabetes, and risk of metabolic syndrome (Schultz et al., 2007, Tandon et al., 2008).

In contrast, patients treated with mGluR $2 / 3$ agonists did not display the side effects commonly associated with current dopaminergic antipsychotics. For example, LY2140023 was generally well tolerated and appeared to have a low association with adverse events related to dopamine D2 receptor antagonism (e.g., EPS) (Mezler, Geneste, 2010). A potential association of LY2140023 treatment and seizure events has been identified, although an accurate and reliable understanding of the incidence of these events requires further clinical testing (Kinon and Gomez, 2013). In addition, in patients treated with LY2140023 or placebo, Ayan-Oshiodi et al. reported no clear trends for increased treatmentemergent adverse events (TEAEs) incidence occurring with higher doses of LY2140023 in both single-dose and multiple-dose treatment groups. The TEAEs with the highest incidence were gastrointestinal and nervous system events, but no serious adverse events occurred, and 
most TEAEs were mild in severity and transient in nature. There were also no clinically significant changes in electroencephalograms in subjects receiving LY2140023, and it was generally well tolerated in healthy subjects (Ayan-Oshodi et al., 2012). Furthermore, there was no evidence of withdrawal symptoms in subjects with the abrupt discontinuation of 4week LY2140023 administration (Stauffer et al., 2014).

The safety, tolerability and potential therapeutic effects of JNJ-40411813/ADX-71149, a mGluR2 PAM (NCT01323205), are also being investigated in patients with SZ (Chue and Lalonde, 2014). The field is waiting for the outcome, although preliminary Phase IIa results suggest potential in the treatment of negative symptoms; a trend toward separation from placebo was observed after 1 month at moderate doses of the investigational drug used as an adjunct to antipsychotics (Chue and Lalonde, 2014) (see De Boer P, Sinha V, Hoeben E, et al. Characterization of the clinical effect of a positive allosteric modulator of the metabotropic glutamate receptor-2 [poster \#998]. Presented at the 68th Annual Conference of the Society of Biological Psychiatry; May 16-18, 2013; San Francisco, CA).

Despite the low side effects, mGluR2/3 agonists' efficacy in SZ patients did not seem to be better than current antipsychotics, at least as a monotherapy. LY2140023 failed to bring a more significant improvement on either positive or negative symptoms compared with other standard antipsychotics (Adams, Kinon, 2013, Adams, Zhang, 2014, Stauffer et al., 2013). In a long-term, phase 2 comparative safety study of LY2140023 versus atypical antipsychotic standard of care (SOC: olanzapine, risperidone, or aripiprazole) in patients with SZ, Adams et al (Adams, Kinon, 2013) reported that there was no statistically significant difference between LY2140023 and SOC for time to discontinuation due to lack of tolerability. The incidence of serious adverse events was comparable between groups. LY2140023-treated patients reported significantly more TEAEs of vomiting, agitation, and dyspepsia, while SOC-treated patients reported significantly more akathisia and weight gain. Improvement in PANSS total score over the initial 6 to 8 weeks of treatment was similar between groups, but improvement was significantly greater in the SOC group at 24-week endpoint. LY2140023 and SOC groups had comparable negative symptom improvement at 24-week endpoint. In another 24-week, multicenter, randomized, double-blind, Phase 3 study, they compared LY2140023 with aripiprazone, an atypical antipsychotic, on efficacy and various safety measures, including serious adverse events (SAEs), discontinuation due to adverse events (AEs), TEAEs, EPS, and suicide-related thoughts and behaviors. Consistently, LY2140023 also showed a significantly lower change in PANSS total scores, significantly higher incidences of SAEs and discontinuation due to AEs compared with aripiprazole. No statistically significant differences in the incidence of TEAEs, EPS, or suicidal ideation or behavior were noted between treatment groups (Adams, Zhang, 2014). It should be noted that patients in both studies were not selected per Howes and Kapur criteria (Howes and Kapur, 2014). It would be interesting to see whether mGluR2/3 agonists are more effective after the patients are grouped and analyzed by dopamine-drug responders versus non-responders. 


\section{Potential of using mGluR2/3 agonist as adjunctive to antipsychotics and the promise for pharmacogenomic treatment}

As discussed above, LY2140023 is an mGluR2/3 full agonist that initially appeared promising (Patil, Zhang, 2007), but ultimately provided disappointing results as a monotherapy in acute psychosis (Downing, Kinon, 2014). Given that mGluR2/3 agonists fail to generate persistent antipsychotic effects in different experiments, mGluR2/3 agonists might not be an optimal candidate as a solitary treatment for SZ, at least for those patients in late stage with clear psychosis at a hyperdopaminergic state. However, the drug may be effective as an adjunct (such as d-serine, glycine, glycine transporter 1 inhibitor, electroconvulsive therapy, etc.) therapy to currently approved antipsychotics (Chue and Lalonde, 2014). Stauffer et al tested this idea, but found no significant difference with LY2140023 as an adjunctive treatment for patients with prominent negative symptoms of SZ compared to placebo (Stauffer, Millen, 2013). As a result, the development program of this compound has been terminated. It should be pointed out that a growing number of studies have investigated the efficacy of novel, adjunctive pharmacotherapies for treatment of cognitive deficits in SZ with conflicting results (Choi et al., 2013). The lack of efficacious pharmacological treatments for the negative and cognitive symptoms certainly represents a significant unmet need, especially considering the importance of these symptoms on patient outcomes. Hence, further research to identify and characterize novel pharmacological treatments (such as the potential of mGluR2 agonist and PAM) for negative and cognitive symptoms is greatly needed (Chue and Lalonde, 2014).

Another consideration for the $\mathrm{SZ}$ treatment is the evaluation technique. The most widely used methods to assess mGluR2/3 agonists' outcome of SZ treatment is behavioral testing. It is well known that results of behavioral tests can be subjective and variable, and this may partially explain the contradictory results performed by different groups. Given that SZ is such a heterogeneous disease with great varieties in terms of etiology, risk factors, pathological processes, onset time, and disease stages and symptoms, more objective indicators of mGluR2/3 agonists' efficacy in SZ is urgently needed. Responding to this need for objective measures of individual differences in drug responses are pharmacogenetics.

These studies aid in discovering the DNA determinants of which influence drug efficacy and tolerability. Given that both type- 2 and 3 metabotropic glutamate receptor gene (GRM 2 and 3) single nucleotide polymorphisms (SNPs) have been associated with cognitive performance and prefrontal cortex activity in SZ patients (Bishop, Reilly, 2015, Egan, Straub, 2004, Harrison, Lyon, 2008, Joo, Shibata, 2001, Kordi-Tamandani, Dahmardeh, 2013, Mossner, Schuhmacher, 2008), it would be valuable to use pharmacogenomics to aid in finding the proper treatments for individual patients with different genetic profiles. In fact, a recent study examined the pharmacogenetic relationships between GRM3 and selected variants in relevant dopamine genes with changes in spatial working memory and SZ symptoms after treatment. Interestingly, they found that working memory performance worsened after antipsychotic risperidone treatment. The worsening was associated with GRM3 rs1468412, but the negative symptom improvement was associated with GRM3 rs6465084. In contrast, there were no pharmacogenetic associations between DRD2/ANKK1 and COMT with working memory changes or symptom response to treatment (Bishop, 
Reilly, 2015). This study provided direct pharmacogenetic associations of the GRM3 gene with working memory and the clinical response to antipsychotics in first-episode SZ. This information is useful in identifying patients susceptible to adverse cognitive outcomes associated with antipsychotic treatment and suggests that glutamatergic mechanisms contribute to such effects. However, other studies have not provided such a promising outcome in SZ pharmacogenomics. A recent pharmacogenetic analysis of the mGlu2/3 agonist LY2140023 in the treatment of SZ reported that 23 SNPs were associated with a change in PANSS in response to LY2140023 at 28 days in SZ patients, and 16 of these SNPs were located in the serotonin 2A receptor (HTR2A), suggesting a genetic association exists between SNPs in several genes and LY2140023 treatment (Liu et al., 2012).

Moreover, in an assessment of SZ endophenotypes, patients of the AA genotype performed poorly in the digit symbol test, a measure of attention. This study provides further evidence for the potential importance of the glutamate receptor GRM3 in SZ, and indicates that the novel antipsychotic LY2140023 may actually be targeting a pathogenic pathway of SZ (Mossner, Schuhmacher, 2008). At this point, therapeutic outcomes of several psychotropic drugs have been weakly linked to specific genetic variants without independent replication (Hamilton, 2015). Additional clinical trials are needed to establish replication of these results.

\section{Conclusion and Insights}

This review summarizes mGluR2/3 agonists' mechanisms of action, mGluR2 and mGluR3's distinct properties and roles in neuropsychiatry and neuroprotection. It also analyzes the potential and status of targeting mGluR2/3 for SZ treatment.

Despite the progress that has been made, many questions still exist, including the effective and safe window of mGluR2/3 agonists in different developmental periods, the difference between mGluR2/3 agonists and more selective mGluR2 agonists and PAMs, as well as the comparison between mGluR2/3 agonists and other antipsychotic drugs. More specifically, it is unknown whether the opposite effects of $\mathrm{mGluR} 2 / 3$ on pre- and postsynaptic sites could explain the failed action in improving SZ symptoms in clinical trials. Are the effects of mGluR2/3 agonist cell-type (excitatory pyramidal neurons versus inhibitory GABAergic interneurons) and brain region (PFC, hippocampus, ventral tegmental area, and other limbic areas) specific? Are the effects of mGluR2/3 agonist age- and/or SZ stage-dependent? Answering these questions in the future will certainly not only enhance our understanding of the mGluR2/3 effects in brain function but also provide better insights into the development of novel compounds targeting mGluR $2 / 3$ for clinical intervention of SZ. Only by solving these mechanistic puzzles can we put mGluR2/3 agonists into clinical trials and provide the optimal therapeutic benefit for individuals afflicted with SZ or other related psychiatric disorders.

In summary, as a potential non-dopaminergic "antipsychotic" drug, pharmacological activation of mGluR2 or mGluR3 still holds promise in alleviating symptoms of SZ. Especially, given the low side effects and high tolerability profile, selective mGluR2 agonist and mGluR2 PAM are still considered promising candidates for pharmacogenomic treatment or as an adjunct to current antipsychotic drugs in the treatment of SZ, particularly 
for cognitive and negative symptoms. The failure of current clinical trials should not be interpreted as a default termination of all potential studies on group II mGluRs because as discussed above, the precise manner of the execution of a clinical trial can have profound consequences for the ultimate outcome of the trial. Based on the literature review, we argue that until the mechanisms associated with mGluR 2 or mGluR3, individually or jointly as mGluR2/3, are clearly elucidated, it is important to continue the study of mGluR2/3 as a therapeutic target for SZ.

\section{Acknowledgments}

This study was supported by grant R01MH085666 to W.J. Gao from the National Institutes of Health, USA; NSFC81271476 and 111 Project B13037 to F. Li, and NSFC81372107 to X.Q. Hu from the Natural Science Foundation of China.

\section{Abbreviations}

3,5-DHPG

5-HT

AC

ACPD

alpha-MPT

AMPA

AMPH

APDC

ASST

ATP

BINA

cAMP

Csk

DA

DCG-IV

DIV

DOI

DRL72

DTI

Erk1/2

fEPSP

GABA 3,5-dihydroxyphenylglycine

5-hydroxytryptamine or serotonin

adenylate cyclase

1-amino-1,3-dicarboxycyclopentane

alpha-methyl-DL-p-tyrosine methyl ester

a-amino-3-hydroxy-5-methyl-4-isoxazolepropionic acid

amphetamine

dihydroxyphenylglycine

attentional set-shifting task

cytosolic adenosine triphosphate

biphenylindanone A

cyclic-adenosine monophosphate

c-terminal of Src kinase

dopamine

(2S, $1^{\prime} \mathrm{R}, 2^{\prime}$ R, $\left.3^{\prime} \mathrm{R}\right)$-2-(2,3-dicarboxycyclopropyl) glycine

days in vitro

2,5-dimethoxy-4-iodoamphetamine

differential reinforcement of a low-rate $72 \mathrm{~s}$

diffusion tensor imaging

Extracellular signal-regulated kinase1/2

field excitatory post-synaptic potential

gama-aminobutyric acid

Prog Neuropsychopharmacol Biol Psychiatry. Author manuscript; available in PMC 2016 July 03. 


\begin{tabular}{|c|c|}
\hline Gsk-3 $\beta$ & glycogen synthase kinase $3 \beta$ \\
\hline HSP & heat shock protein \\
\hline i.c.v & intracerebroventricular \\
\hline I.P & intraperitoneal \\
\hline KO & knock out \\
\hline LTD & long term depression \\
\hline LTP & long term potentiation \\
\hline МАPH & methamphetamine \\
\hline mGluRs & metabotropic glutamate receptors \\
\hline MK-801 & dizocilpine \\
\hline NMDA & N-methyl-D-aspartate \\
\hline NSF & N-ethylmaleimide-sensitive factor \\
\hline P.O & per os \\
\hline PAMs & positive allosteric modulators \\
\hline PCP & phencyclidine \\
\hline PCPA & DL-p-chlorophenylalanine \\
\hline PD & parkinson's disease \\
\hline PKA & protein kinase A \\
\hline PKC & protein kinase $\mathrm{C}$ \\
\hline PVT & paraventricular thalamic nucleus \\
\hline s.c & subcutaneous \\
\hline SLM & stratum lacunosum moleculare \\
\hline SNAP & soluble NSF activating protein \\
\hline SNARE & soluble NSF activating protein receptor \\
\hline SNP & single nucleotide polymorphism \\
\hline SZ & schizophrenia \\
\hline TAP & temporo-ammonic path \\
\hline VAMP & vesicle-associated membrane protein \\
\hline
\end{tabular}

\section{References}

Adams DH, Kinon BJ, Baygani S, Millen BA, Velona I, Kollack-Walker S, et al. A long-term, phase 2, multicenter, randomized, open-label, comparative safety study of pomaglumetad methionil (LY2140023 monohydrate) versus atypical antipsychotic standard of care in patients with schizophrenia. BMC Psychiatry. 2013; 13:143. [PubMed: 23694720]

Prog Neuropsychopharmacol Biol Psychiatry. Author manuscript; available in PMC 2016 July 03. 
Adams DH, Zhang L, Millen BA, Kinon BJ, Gomez J-C. Pomaglumetad Methionil (LY2140023 Monohydrate) and Aripiprazole in Patients with Schizophrenia: A Phase 3, Multicenter, DoubleBlind Comparison. Schizophrenia Research and Treatment. 2014; 2014:758212. [PubMed: 24772351]

Anwyl R. Metabotropic glutamate receptors: electrophysiological properties and role in plasticity. Brain Res Reviews. 1999; 29:83-120.

Auclair A, Cotecchia S, Glowinski J, Tassin JP. D-amphetamine fails to increase extracellular dopamine levels in mice lacking alpha 1b-adrenergic receptors: relationship between functional and nonfunctional dopamine release. The Journal of neuroscience: the official journal of the Society for Neuroscience. 2002; 22:9150-4. [PubMed: 12417637]

Aultman JM, Moghaddam B. Distinct contributions of glutamate and dopamine receptors to temporal aspects of rodent working memory using a clinically relevant task. Psychopharmacology (Berl). 2001; 153:353-64. [PubMed: 11271408]

Ayan-Oshodi M, Wondmagegnehu ET, Lowe SL, Kryzhanovskaya L, Walker DJ, Kinon BJ. Adverse events in healthy subjects exposed to single and multiple doses of LY2140023 monohydrate: pooled results from 10 phase 1 studies. J Clin Psychopharmacol. 2012; 32:408-11. [PubMed: 22544017]

Bishop JR, Reilly JL, Harris MS, Patel SR, Kittles R, Badner JA, et al. Pharmacogenetic associations of the type-3 metabotropic glutamate receptor (GRM3) gene with working memory and clinical symptom response to antipsychotics in first-episode schizophrenia. Psychopharmacology (Berl). 2015; 232:145-54. [PubMed: 25096017]

Bruno V, Battaglia G, Casabona G, Copani A, Caciagli F, Nicoletti F. Neuroprotection by glial metabotropic glutamate receptors is mediated by transforming growth factor-beta. J Neurosci. 1998; 18:9594-600. [PubMed: 9822720]

Bruno V, Battaglia G, Copani A, D’Onofrio M, Di Iorio P, De Blasi A, et al. Metabotropic glutamate receptor subtypes as targets for neuroprotective drugs. J Cereb Blood Flow Metab. 2001; 21:101333. [PubMed: 11524608]

Bruno V, Sureda FX, Storto M, Casabona G, Caruso A, Knopfel T, et al. The neuroprotective activity of group-II metabotropic glutamate receptors requires new protein synthesis and involves a glialneuronal signaling. J Neurosci. 1997; 17:1891-7. [PubMed: 9045718]

Carpenter WT, Koenig JI. The evolution of drug development in schizophrenia: past issues and future opportunities. Neuropsychopharmacology. 2008; 33:2061-79. [PubMed: 18046305]

Cartmell J, Monn JA, Schoepp DD. The metabotropic glutamate 2/3 receptor agonists LY354740 and LY379268 selectively attenuate phencyclidine versus d-amphetamine motor behaviors in rats. J Pharmacol Exp Ther. 1999; 291:161-70. [PubMed: 10490900]

Cartmell J, Monn JA, Schoepp DD. Attenuation of specific PCP-evoked behaviors by the potent mGlu2/3 receptor agonist, LY379268 and comparison with the atypical antipsychotic, clozapine. Psychopharmacology (Berl). 2000a; 148:423-9. [PubMed: 10928316]

Cartmell J, Monn JA, Schoepp DD. The mGlu(2/3) receptor agonist LY379268 selectively blocks amphetamine ambulations and rearing. European journal of pharmacology. 2000b; 400:221-4. [PubMed: 10988337]

Cartmell J, Schoepp DD. Regulation of neurotransmitter release by metabotropic glutamate receptors. J of Neurochem. 2000; 75:889-907. [PubMed: 10936169]

Chaki S, Ago Y, Palucha-Paniewiera A, Matrisciano F, Pilc A. mGlu2/3 and mGlu5 receptors: Potential targets for novel antidepressants. Neuropharmacology. 2013; 66:40-52. [PubMed: 22640631]

Chartoff EH, Heusner CL, Palmiter RD. Dopamine is not required for the hyperlocomotor response to NMDA receptor antagonists. Neuropsychopharmacology: official publication of the American College of Neuropsychopharmacology. 2005; 30:1324-33. [PubMed: 15688082]

Chen Q, He G, Chen Q, Wu S, Xu Y, Feng G, et al. A case-control study of the relationship between the metabotropic glutamate receptor 3 gene and schizophrenia in the Chinese population. Schizophr Res. 2005; 73:21-6. [PubMed: 15567072]

Cheng J, Liu W, Duffney LJ, Yan Z. SNARE proteins are essential in the potentiation of NMDA receptors by group II metabotropic glutamate receptors. J Physiol. 2013; 591:3935-47. [PubMed: 23774277] 
Choi KH, Wykes T, Kurtz MM. Adjunctive pharmacotherapy for cognitive deficits in schizophrenia: meta-analytical investigation of efficacy. Br J Psychiatry. 2013; 203:172-8. [PubMed: 23999481]

Chue P, Lalonde JK. Addressing the unmet needs of patients with persistent negative symptoms of schizophrenia: emerging pharmacological treatment options. Neuropsychiatric disease and treatment. 2014; 10:777-89. [PubMed: 24855363]

Cid JM, Tresadern G, Vega JA, de Lucas AI, Matesanz E, Iturrino L, et al. Discovery of 3cyclopropylmethyl-7-(4-phenylpiperidin-1-yl)-8-trifluoromethyl[1,2,4]triazolo[4,3-a]pyridine (JNJ-42153605): a positive allosteric modulator of the metabotropic glutamate 2 receptor. Journal of medicinal chemistry. 2012; 55:8770-89. [PubMed: 23072213]

Conn PJ, Lindsley CW, Jones CK. Activation of metabotropic glutamate receptors as a novel approach for the treatment of schizophrenia. Trends in pharmacological sciences. 2009; 30:25-31. [PubMed: 19058862]

Conn PJ, Pin JP. Pharmacology and functions of metabotropic glutamate receptors. Annu Rev Pharmacol Toxicol. 1997; 37:205-37. [PubMed: 9131252]

Copeland CS, Neale SA, Salt TE. Positive allosteric modulation reveals a specific role for mGlu2 receptors in sensory processing in the thalamus. J Physiol. 2012; 590:937-51. [PubMed: 22199165]

Corti C, Battaglia G, Molinaro G, Riozzi B, Pittaluga A, Corsi M, et al. The use of knock-out mice unravels distinct roles for mGlu2 and mGlu3 metabotropic glutamate receptors in mechanisms of neurodegeneration/neuroprotection. J Neurosci. 2007; 27:8297-308. [PubMed: 17670976]

de Bartolomeis A, Buonaguro EF, Iasevoli F. Serotonin-glutamate and serotonin-dopamine reciprocal interactions as putative molecular targets for novel antipsychotic treatments: from receptor heterodimers to postsynaptic scaffolding and effector proteins. Psychopharmacology (Berl). 2013; 225:1-19. [PubMed: 23179966]

Dhanya RP, Sidique S, Sheffler DJ, Nickols HH, Herath A, Yang L, et al. Design and synthesis of an orally active metabotropic glutamate receptor subtype-2 (mGluR2) positive allosteric modulator (PAM) that decreases cocaine self-administration in rats. J Med Chem. 2011; 54:342-53. [PubMed: 21155570]

Downing AM, Kinon BJ, Millen BA, Zhang L, Liu L, Morozova MA, et al. A double-blind, placebocontrolled comparator study of LY2140023 monohydrate in patients with schizophrenia. BMC Psychiatry. 2014; 14:351.

Durand D, Carniglia L, Caruso C, Lasaga M. mGlu3 receptor and astrocytes: Partners in neuroprotection. Neuropharmacology. 2013; 66:1-11. [PubMed: 22564439]

Egan MF, Straub RE, Goldberg TE, Yakub I, Callicott JH, Hariri AR, et al. Variation in GRM3 affects cognition, prefrontal glutamate, and risk for schizophrenia. Proc Natl Acad Sci U S A. 2004; 101:12604-9. [PubMed: 15310849]

Fell MJ, McKinzie DL, Monn JA, Svensson KA. Group II metabotropic glutamate receptor agonists and positive allosteric modulators as novel treatments for schizophrenia. Neuropharmacology. 2012; 62:1473-83. [PubMed: 21704048]

Fell MJ, Perry KW, Falcone JF, Johnson BG, Barth VN, Rash KS, et al. In vitro and in vivo evidence for a lack of interaction with Dopamine D2 receptors by the mGlu2/3 receptor agonists LY354740 and LY379268. J Pharmacol Exp Ther. 2009; 331:1126-36. [PubMed: 19755662]

Fell MJ, Svensson KA, Johnson BG, Schoepp DD. Evidence for the role of metabotropic glutamate (mGlu) 2 not mGlu3 receptors in the preclinical antipsychotic pharmacology of the mGlu2/3 receptor agonist (-)-(1R,4S,5S,6S)-4-amino-2-sulfonylbicyclo[3.1.0]hexane-4,6-dicarboxylic acid (LY404039). The Journal of pharmacology and experimental therapeutics. 2008; 326:209-17. [PubMed: 18424625]

Frank E, Newell KA, Huang XF. Density of metabotropic glutamate receptors 2 and 3 (mGluR2/3) in the dorsolateral prefrontal cortex does not differ with schizophrenia diagnosis but decreases with age. Schizophr Res. 2011; 128:56-60. [PubMed: 21334855]

Fribourg M, Moreno José L, Holloway T, Provasi D, Baki L, Mahajan R, et al. Decoding the Signaling of a GPCR Heteromeric Complex Reveals a Unifying Mechanism of Action of Antipsychotic Drugs. Cell. 2011; 147:1011-23. [PubMed: 22118459] 
Fujioka R, Nii T, Iwaki A, Shibata A, Ito I, Kitaichi K, et al. Comprehensive behavioral study of mGluR3 knockout mice: implication in schizophrenia related endophenotypes. Mol Brain. 2014; 7:31. [PubMed: 24758191]

Galici R, Echemendia NG, Rodriguez AL, Conn PJ. A selective allosteric potentiator of metabotropic glutamate (mGlu) 2 receptors has effects similar to an orthosteric mGlu2/3 receptor agonist in mouse models predictive of antipsychotic activity. J Pharmacol Exp Ther. 2005; 315:1181-7. [PubMed: 16123306]

Ghose S, Gleason KA, Potts BW, Lewis-Amezcua K, Tamminga CA. Differential expression of metabotropic glutamate receptors 2 and 3 in schizophrenia: a mechanism for antipsychotic drug action? Am J Psychiatry. 2009; 166:812-20. [PubMed: 19487395]

Gonzalez-Maeso J, Ang RL, Yuen T, Chan P, Weisstaub NV, Lopez-Gimenez JF, et al. Identification of a serotonin/glutamate receptor complex implicated in psychosis. Nature. 2008; 452:93-7. [PubMed: 18297054]

Hamilton SP. The Promise of Psychiatric Pharmacogenomics. Biol Psychiatry. 2015; 77:29-35. [PubMed: 25483343]

Hanna L, Ceolin L, Lucas S, Monn J, Johnson B, Collingridge G, et al. Differentiating the roles of mGlu2 and mGlu3 receptors using LY541850, an mGlu2 agonist/mGlu3 antagonist. Neuropharmacology. 2013; 66:114-21. [PubMed: 22445601]

Harich S, Gross G, Bespalov A. Stimulation of the metabotropic glutamate $2 / 3$ receptor attenuates social novelty discrimination deficits induced by neonatal phencyclidine treatment. Psychopharmacology (Berl). 2007; 192:511-9. [PubMed: 17318501]

Harrison PJ, Lyon L, Sartorius LJ, Burnet PW, Lane TA. The group II metabotropic glutamate receptor 3 (mGluR3, mGlu3, GRM3): expression, function and involvement in schizophrenia. J Psychopharmacol. 2008; 22:308-22. [PubMed: 18541626]

Higgins GA, Ballard TM, Kew JN, Richards JG, Kemp JA, Adam G, et al. Pharmacological manipulation of mGlu2 receptors influences cognitive performance in the rodent. Neuropharmacology. 2004; 46:907-17. [PubMed: 15081787]

Hikichi H, Kaku A, Karasawa J, Chaki S. Stimulation of metabotropic glutamate (mGlu) 2 receptor and blockade of mGlu1 receptor improve social memory impairment elicited by MK-801 in rats. Journal of pharmacological sciences. 2013; 122:10-6. [PubMed: 23603933]

Hopkins CR. Is there a path forward for mGlu(2) positive allosteric modulators for the treatment of schizophrenia? ACS Chem Neurosci. 2013; 4:211-3. [PubMed: 23421671]

Howes OD, Kapur S. The dopamine hypothesis of schizophrenia: version III--the final common pathway. Schizophr Bull. 2009; 35:549-62. [PubMed: 19325164]

Howes OD, Kapur S. A neurobiological hypothesis for the classification of schizophrenia: type A (hyperdopaminergic) and type B (normodopaminergic). Br J Psychiatry. 2014; 205:1-3. [PubMed: 24986384]

Imre G, Salomons A, Jongsma M, Fokkema DS, Den Boer JA, Ter Horst GJ. Effects of the mGluR2/3 agonist LY379268 on ketamine-evoked behaviours and neurochemical changes in the dentate gyrus of the rat. Pharmacol Biochem Behav. 2006; 84:392-9. [PubMed: 16857251]

Jones CA, Brown AM, Auer DP, Fone KC. The mGluR2/3 agonist LY379268 reverses post-weaning social isolation-induced recognition memory deficits in the rat. Psychopharmacology (Berl). 2011; 214:269-83. [PubMed: 20607219]

Joo A, Shibata H, Ninomiya H, Kawasaki H, Tashiro N, Fukumaki Y. Structure and polymorphisms of the human metabotropic glutamate receptor type 2 gene (GRM2): analysis of association with schizophrenia. Mol Psychiatry. 2001; 6:186-92. [PubMed: 11317221]

Kinon BJ, Gomez JC. Clinical development of pomaglumetad methionil: a non-dopaminergic treatment for schizophrenia. Neuropharmacology. 2013; 66:82-6. [PubMed: 22722029]

Klodzinska A, Bijak M, Tokarski K, Pilc A. Group II mGlu receptor agonists inhibit behavioural and electrophysiological effects of DOI in mice. Pharmacology, biochemistry, and behavior. 2002; 73:327-32.

Kordi-Tamandani DM, Dahmardeh N, Torkamanzehi A. Evaluation of hypermethylation and expression pattern of GMR2, GMR5, GMR8, and GRIA3 in patients with schizophrenia. Gene. 2013; 515:163-6. [PubMed: 23149219] 
Krystal JH, Abi-Saab W, Perry E, D’Souza DC, Liu N, Gueorguieva R, et al. Preliminary evidence of attenuation of the disruptive effects of the NMDA glutamate receptor antagonist, ketamine, on working memory by pretreatment with the group II metabotropic glutamate receptor agonist, LY354740, in healthy human subjects. Psychopharmacology (Berl). 2005; 179:303-9. [PubMed: 15309376]

Lainiola M, Procaccini C, Linden AM. mGluR3 knockout mice show a working memory defect and an enhanced response to MK-801 in the T- and Y-maze cognitive tests. Behav Brain Res. 2014; 266:94-103. [PubMed: 24631392]

Lavreysen H, Langlois X, Ahnaou A, Drinkenburg W, te Riele P, Biesmans I, et al. Pharmacological characterization of JNJ-40068782, a new potent, selective, and systemically active positive allosteric modulator of the mGlu2 receptor and its radioligand [3H]JNJ-40068782. J Pharmacol Exp Ther. 2013; 346:514-27. [PubMed: 23766542]

Lee H, Dvorak D, Kao H-Y, Duffy Áine M, Scharfman Helen E, Fenton André A. Early cognitive experience prevents adult deficits in a neurodevelopmental schizophrenia model. Neuron. 2012; 75:714-24. [PubMed: 22920261]

Li Y-C, Kellendonk C, Simpson EH, Kandel ER, Gao W-J. D2 receptor overexpression in the striatum leads to a deficit in inhibitory transmission and dopamine sensitivity in mouse prefrontal cortex. Proceedings of the National Academy of Sciences. 2011; 108:12107-12.

Li YC, Gao WJ. GSK-3beta activity and hyperdopamine-dependent behaviors. Neurosci Biobehav Rev. 2011; 35:645-54. [PubMed: 20727368]

Li YC, Wang MJ, Gao WJ. Hyperdopaminergic modulation of inhibitory transmission is dependent on GSK-3beta signaling-mediated trafficking of GABA(A) receptors. J Neurochem. 2012; 122:30820. [PubMed: 22676038]

Li YC, Xi D, Roman J, Huang YQ, Gao WJ. Activation of glycogen synthase kinase-3 beta is required for hyperdopamine and D2 receptor-mediated inhibition of synaptic NMDA receptor function in the rat prefrontal cortex. J Neurosci. 2009; 29:15551-63. [PubMed: 20007479]

Lindsley CW, Shipe WD, Wolkenberg SE, Theberge CR, Williams DL Jr, Sur C, et al. Progress towards validating the NMDA receptor hypofunction hypothesis of schizophrenia. Curr Top Med Chem. 2006; 6:771-85. [PubMed: 16719816]

Lisman JE, Coyle JT, Green RW, Javitt DC, Benes FM, Heckers S, et al. Circuit-based framework for understanding neurotransmitter and risk gene interactions in schizophrenia. Trends in Neurosci. 2008; 31:234-42.

Liu W, Downing AC, Munsie LM, Chen P, Reed MR, Ruble CL, et al. Pharmacogenetic analysis of the mGlu2/3 agonist LY2140023 monohydrate in the treatment of schizophrenia. Pharmacogenomics J. 2012; 12:246-54. [PubMed: 21173788]

Lorrain DS, Baccei CS, Bristow LJ, Anderson JJ, Varney MA. Effects of ketamine and N-methyl-Daspartate on glutamate and dopamine release in the rat prefrontal cortex: modulation by a group II selective metabotropic glutamate receptor agonist LY379268. Neuroscience. 2003a; 117:697-706. [PubMed: 12617973]

Lorrain DS, Schaffhauser H, Campbell UC, Baccei CS, Correa LD, Rowe B, et al. Group II mGlu receptor activation suppresses norepinephrine release in the ventral hippocampus and locomotor responses to acute ketamine challenge. Neuropsychopharmacology: official publication of the American College of Neuropsychopharmacology. 2003b; 28:1622-32. [PubMed: 12825094]

Marek GJ. Metabotropic glutamate2/3 (mGlu2/3) receptors, schizophrenia and cognition. European Journal of Pharmacology. 2010; 639:81-90. [PubMed: 20371229]

Matosin N, Fernandez-Enright F, Frank E, Deng C, Wong J, Huang XF, et al. Metabotropic glutamate receptor mGluR2/3 and mGluR5 binding in the anterior cingulate cortex in psychotic and nonpsychotic depression, bipolar disorder and schizophrenia: implications for novel mGluR-based therapeutics. J Psychiatry Neurosci. 2014; 39:407-16. [PubMed: 24949866]

Matrisciano F, Tueting P, Maccari S, Nicoletti F, Guidotti A. Pharmacological activation of group-II metabotropic glutamate receptors corrects a schizophrenia-like phenotype induced by prenatal stress in mice. Neuropsychopharmacology. 2012; 37:929-38. [PubMed: 22089319] 
Mezler M, Geneste H, Gault L, Marek GJ. LY-2140023, a prodrug of the group II metabotropic glutamate receptor agonist LY-404039 for the potential treatment of schizophrenia. Curr Opin Investig Drugs. 2010; 11:833-45.

Michalon A, Sidorov M, Ballard Theresa M, Ozmen L, Spooren W, Wettstein Joseph G, et al. Chronic Pharmacological mGlu5 Inhibition Corrects Fragile X in Adult Mice. Neuron. 2012; 74:49-56. [PubMed: 22500629]

Miyamoto S, Duncan GE, Marx CE, Lieberman JA. Treatments for schizophrenia: a critical review of pharmacology and mechanisms of action of antipsychotic drugs. Mol Psychiatry. 2005; 10:79104. [PubMed: 15289815]

Moghaddam B. Targeting metabotropic glutamate receptors for treatment of the cognitive symptoms of schizophrenia. Psychopharmacol (Berl). 2004; 174:39-44.

Moghaddam B, Adams BW. Reversal of phencyclidine effects by a group II metabotropic glutamate receptor agonist in rats. Science. 1998; 281:1349-52. [PubMed: 9721099]

Mossner R, Schuhmacher A, Schulze-Rauschenbach S, Kuhn KU, Rujescu D, Rietschel M, et al. Further evidence for a functional role of the glutamate receptor gene GRM3 in schizophrenia. Eur Neuropsychopharmacol. 2008; 18:768-72. [PubMed: 18614340]

Nakazawa K, Zsiros V, Jiang Z, Nakao K, Kolata S, Zhang S, et al. GABAergic interneuron origin of schizophrenia pathophysiology. Neuropharmacology. 2012; 62:1574-83. [PubMed: 21277876]

Nicoletti F, Bruno V, Copani A, Casabona G, Knopfel T. Metabotropic glutamate receptors: a new target for the therapy of neurodegenerative disorders? Trends Neurosci. 1996; 19:267-71. [PubMed: 8799968]

Nikiforuk A, Popik P, Drescher KU, van Gaalen M, Relo AL, Mezler M, et al. Effects of a positive allosteric modulator of group II metabotropic glutamate receptors, LY487379, on cognitive flexibility and impulsive-like responding in rats. J Pharmacol Exp Ther. 2010; 335:665-73. [PubMed: 20739457]

Niswender CM, Conn PJ. Metabotropic glutamate receptors: physiology, pharmacology, and disease. Annu Rev Pharmacol Toxicol. 2010; 50:295-322. [PubMed: 20055706]

Olney JW, Farber NB. Glutamate receptor dysfunction and schizophrenia. Archive General Psychiatry. 1995; 52:998-1007.

Olney JW, Newcomer JW, Farber NB. NMDA receptor hypofunction model of schizophrenia. J Psychiatr Res. 1999; 33:523-33. [PubMed: 10628529]

Patil ST, Zhang L, Martenyi F, Lowe SL, Jackson KA, Andreev BV, et al. Activation of mGlu2/3 receptors as a new approach to treat schizophrenia: a randomized Phase 2 clinical trial. Nature medicine. 2007; 13:1102-7.

Pauli A, Prata DP, Mechelli A, Picchioni M, Fu CH, Chaddock CA, et al. Interaction between effects of genes coding for dopamine and glutamate transmission on striatal and parahippocampal function. Human brain mapping. 2013; 34:2244-58. [PubMed: 22438288]

Petralia RS, Wang YX, Niedzielski AS, Wenthold RJ. The metabotropic glutamate receptors, MGLUR2 and MGLUR3, show unique postsynaptic, presynaptic and glial localizations. Neuroscience. 1996; 71:949-76. [PubMed: 8684625]

Profaci CP, Krolikowski KA, Olszewski RT, Neale JH. Group II mGluR agonist LY354740 and NAAG peptidase inhibitor effects on prepulse inhibition in PCP and D-amphetamine models of schizophrenia. Psychopharmacology. 2011; 216:235-43. [PubMed: 21327758]

Rorick-Kehn LM, Perkins EJ, Knitowski KM, Hart JC, Johnson BG, Schoepp DD, et al. Improved bioavailability of the mGlu2/3 receptor agonist LY354740 using a prodrug strategy: in vivo pharmacology of LY544344. The Journal of pharmacology and experimental therapeutics. 2006; 316:905-13. [PubMed: 16223873]

Rotaru DC, Yoshino H, Lewis DA, Ermentrout GB, Gonzalez-Burgos G. Glutamate receptor subtypes mediating synaptic activation of prefrontal cortex neurons: relevance for schizophrenia. The Journal of neuroscience: the official journal of the Society for Neuroscience. 2011; 31:142-56. [PubMed: 21209199]

Schlumberger C, Schafer D, Barberi C, More L, Nagel J, Pietraszek M, et al. Effects of a metabotropic glutamate receptor group II agonist LY354740 in animal models of positive schizophrenia symptoms and cognition. Behav Pharmacol. 2009; 20:56-66. [PubMed: 19179851] 
Schoepp DD, Jane DE, Monn JA. Pharmacological agents acting at subtypes of metabotropic glutamate receptors. Neuropharmacology. 1999; 38:1431-76. [PubMed: 10530808]

Schultz SH, North SW, Shields CG. Schizophrenia: a review. American family physician. 2007; 75:1821-9. [PubMed: 17619525]

Seeman P, Caruso C, Lasaga M. Dopamine partial agonist actions of the glutamate receptor agonists LY 354,740 and LY 379,268. Synapse. 2008; 62:154-8. [PubMed: 18000815]

Seeman P, Guan H-C. Glutamate agonist LY404,039 for treating schizophrenia has affinity for the dopamine D2High receptor. Synapse. 2009; 63:935-9. [PubMed: 19588471]

Seeman P, Guan HC. Phencyclidine and glutamate agonist LY379268 stimulate dopamine D2 High receptors: D2 basis for schizophrenia. Synapse. 2008; 62:819-28. [PubMed: 18720422]

Snyder MA, Gao W-J. NMDA hypofunction as a convergence point for progression and symptoms of schizophrenia. Frontiers in Cellular Neuroscience. 2013; 7:31. [PubMed: 23543703]

Spooren WP, Gasparini F, van der Putten H, Koller M, Nakanishi S, Kuhn R. Lack of effect of LY314582 (a group 2 metabotropic glutamate receptor agonist) on phencyclidine-induced locomotor activity in metabotropic glutamate receptor 2 knockout mice. Eur J Pharmacol. 2000; 397:R1-2. [PubMed: 10844118]

Stauffer VL, Baygani SK, Kinon BJ, Krikke-Workel JO. A short-term, multicenter, placebocontrolled, randomized withdrawal study of a metabotropic glutamate $2 / 3$ receptor agonist using an electronic patient-reported outcome device in patients with schizophrenia. J Clin Psychopharmacol. 2014; 34:552-8. [PubMed: 25006819]

Stauffer VL, Millen BA, Andersen S, Kinon BJ, Lagrandeur L, Lindenmayer JP, et al. Pomaglumetad methionil: no significant difference as an adjunctive treatment for patients with prominent negative symptoms of schizophrenia compared to placebo. Schizophr Res. 2013; 150:434-41. [PubMed: 24035403]

Swanson CJ, Schoepp DD. The group II metabotropic glutamate receptor agonist (-)-2-oxa-4aminobicyclo[3.1.0.]hexane-4,6-dicarboxylate (LY379268) and clozapine reverse phencyclidineinduced behaviors in monoamine-depleted rats. J Pharmacol Exp Ther. 2002; 303:919-27. [PubMed: 12438510]

Tamaru Y, Nomura S, Mizuno N, Shigemoto R. Distribution of metabotropic glutamate receptor mGluR3 in the mouse CNS: differential location relative to pre- and postsynaptic sites. Neuroscience. 2001; 106:481-503. [PubMed: 11591452]

Tamminga CA. The promise of new drugs for schizophrenia treatment. Can J Psychiatry. 1997; 42:265-73. [PubMed: 9114942]

Tandon R, Keshavan MS, Nasrallah HA. Schizophrenia, "Just the Facts": what we know in 2008 part 1: overview. Schizophrenia research. 2008; 100:4-19. [PubMed: 18291627]

Trepanier C, Lei G, Xie YF, Macdonald JF. Group II metabotropic glutamate receptors modify Nmethyl-D-aspartate receptors via Src kinase. Scientific reports. 2013; 3:926. [PubMed: 23378895]

Tyszkiewicz JP, Gu Z, Wang X, Cai X, Yan Z. Group II metabotropic glutamate receptors enhance NMDA receptor currents via a protein kinase C-dependent mechanism in pyramidal neurones of rat prefrontal cortex. J Physiol. 2004; 554:765-77. [PubMed: 14645456]

Wang MJ, Li YC, Snyder MA, Wang H, Li F, Gao WJ. Group II metabotropic glutamate receptor agonist LY379268 regulates AMPA receptor trafficking in prefrontal cortical neurons. PloS one. 2013; 8:e61787. [PubMed: 23593498]

Weinberger DR. Schizophrenia drug says goodbye to dopamine. Nature medicine. 2007; 13:1018-9.

Winter JC, Eckler JR, Rabin RA. Serotonergic/glutamatergic interactions: the effects of mGlu2/3 receptor ligands in rats trained with LSD and PCP as discriminative stimuli. Psychopharmacology. 2004; 172:233-40. [PubMed: 14598016]

Woolley ML, Pemberton DJ, Bate S, Corti C, Jones DN. The mGlu2 but not the mGlu3 receptor mediates the actions of the mGluR2/3 agonist, LY379268, in mouse models predictive of antipsychotic activity. Psychopharmacology. 2008; 196:431-40. [PubMed: 18057917]

Wright RA, Johnson BG, Zhang C, Salhoff C, Kingston AE, Calligaro DO, et al. CNS distribution of metabotropic glutamate 2 and 3 receptors: transgenic mice and [(3)H]LY459477 autoradiography. Neuropharmacology. 2013; 66:89-98. [PubMed: 22313530] 
Xi D, Li Y-C, Snyder MA, Gao RY, Adelman AE, Zhang W, et al. Group II metabotropic glutamate receptor agonist ameliorates MK-801-induced dysfunction of NMDA receptors via Akt/ GSK-3beta pathway. Neuropsychopharmacol. 2011; 36:1260-74.

Yokoi M, Kobayashi K, Manabe T, Takahashi T, Sakaguchi I, Katsuura G, et al. Impairment of hippocampal mossy fiber LTD in mice lacking mGluR2. Science. 1996; 273:645-7. [PubMed: 8662555] 


\section{Highlights}

- $\mathrm{mGluR} 2 / 3$ as a therapeutic target for schizophrenia

- Working mechanisms of mGluR2/3 agonists in the brain

- Differential role of mGluR2 and mGluR3 in antipsychotic and neuroprotective action

- Studies of mGluR2/3 agonists in animal models of schizophrenia

- mGluR2/3 agonist as adjunct to antipsychotics and promise of pharmacogenomics 


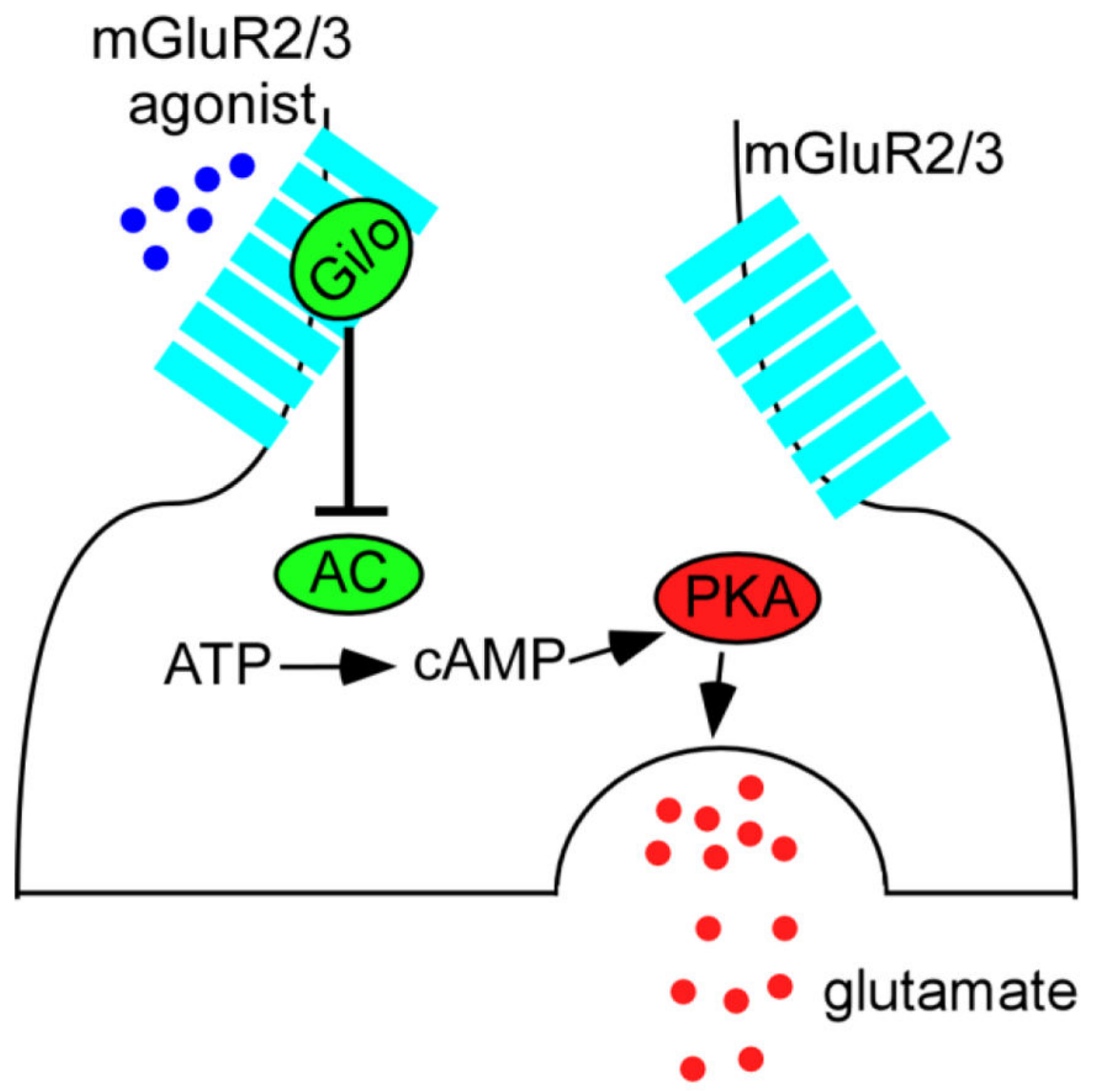

Figure 1.

A schematic summary graph shows that mGluR2/3 agonists reduce glutamate release at presynaptic site by inhibiting AC-cAMP-PKA signaling pathway. 


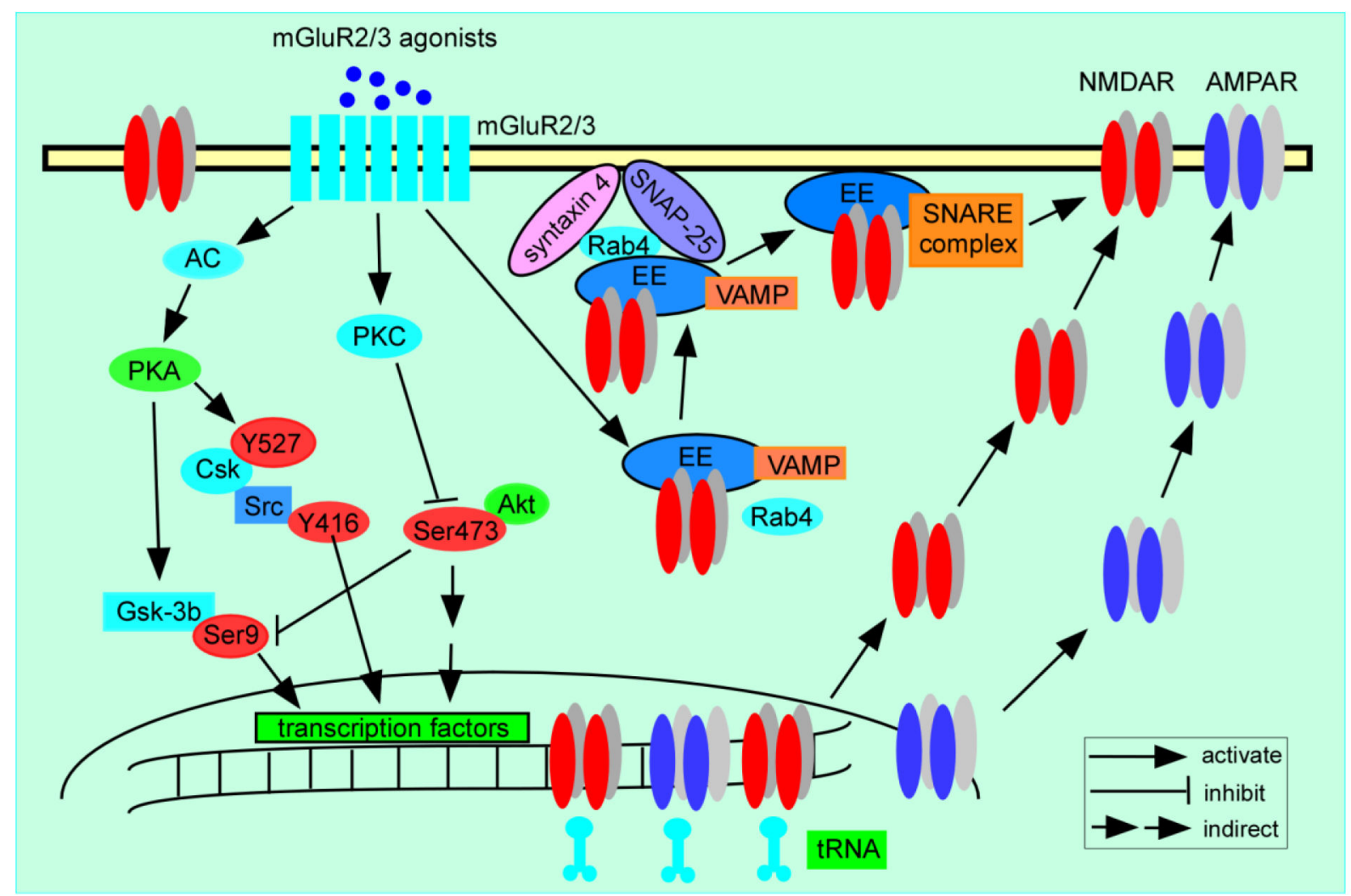

Figure 2.

A schematic summary graph shows the postsynaptic effects of mGluR $2 / 3$ agonists on the regulation of both AMPA and NMDA receptors. The mGluR2/3 agonist APDC significantly increases PKC-mediated phosphorylation of NMDA receptors (Tyszkiewicz, Gu, 2004). APDC also increases the interaction between Rab4 and syntaxin 4, which facilitates the formation of soluble SNARE complexes that is composed of SNAP-25, syntaxin 4 and VAMP at postsynaptic sites, leading to the increased exocytosis of NMDARs (Cheng, Liu, 2013). Moreover, activation of mGluR2/3 inhibits the AC-cAMP-PKA pathway and thereby activates Src-mediated upregulation of NMDAR functions (Trepanier, Lei, 2013). In addition, LY379268 increases the surface expression of AMPA receptors through activating ERK1/2 and GSK-3 $\beta$ signaling pathways (Wang, Li, 2013), directly modulates NMDAR expression and function, as well as reverses MK801-induced NMDAR dysfunction via activation of Akt/Gsk-3ß pathway (Xi, Li, 2011). 


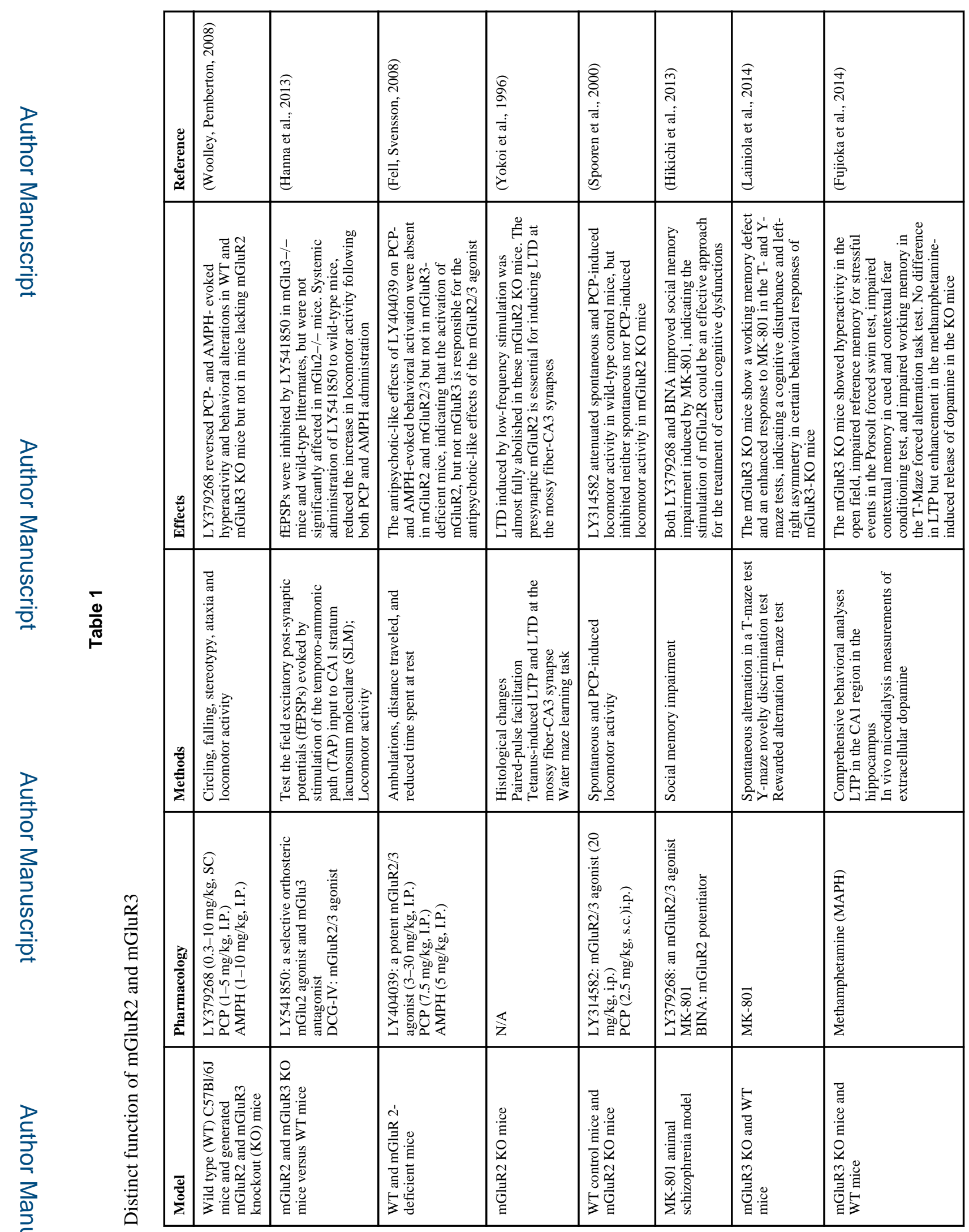

Prog Neuropsychopharmacol Biol Psychiatry. Author manuscript; available in PMC 2016 July 03. 


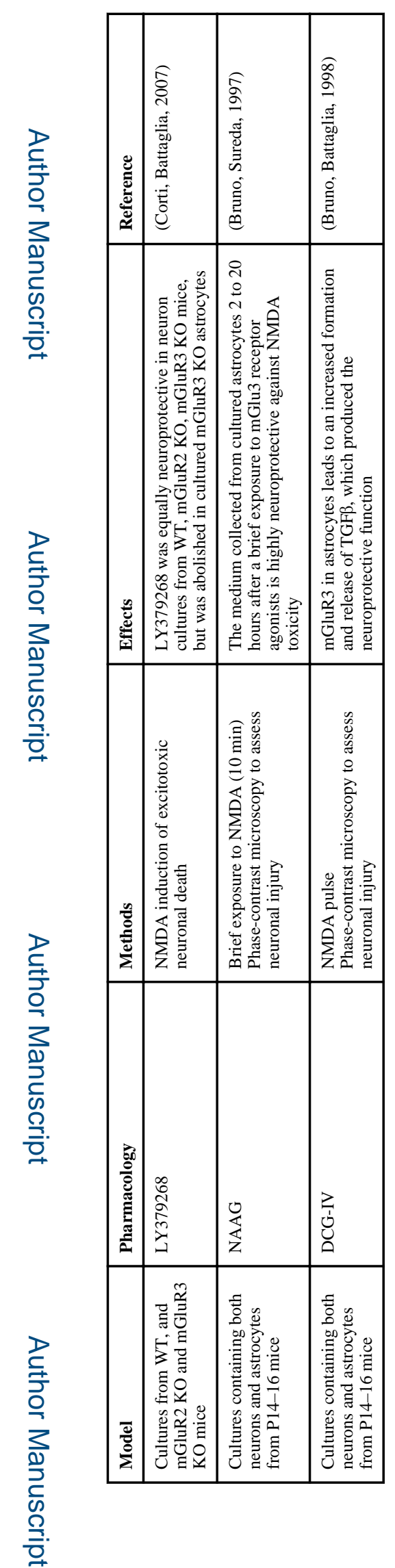

Prog Neuropsychopharmacol Biol Psychiatry. Author manuscript; available in PMC 2016 July 03. 


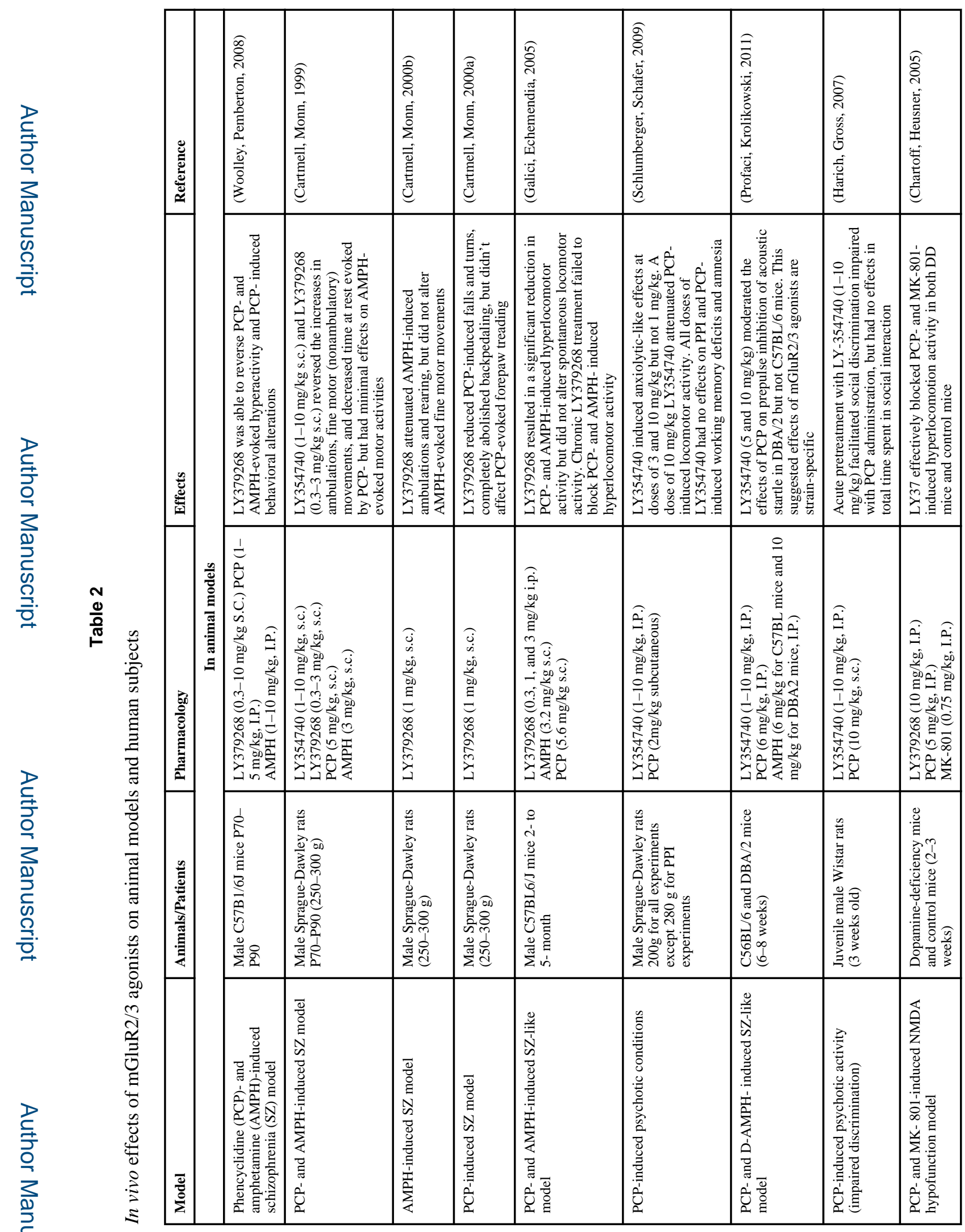

Prog Neuropsychopharmacol Biol Psychiatry. Author manuscript; available in PMC 2016 July 03. 


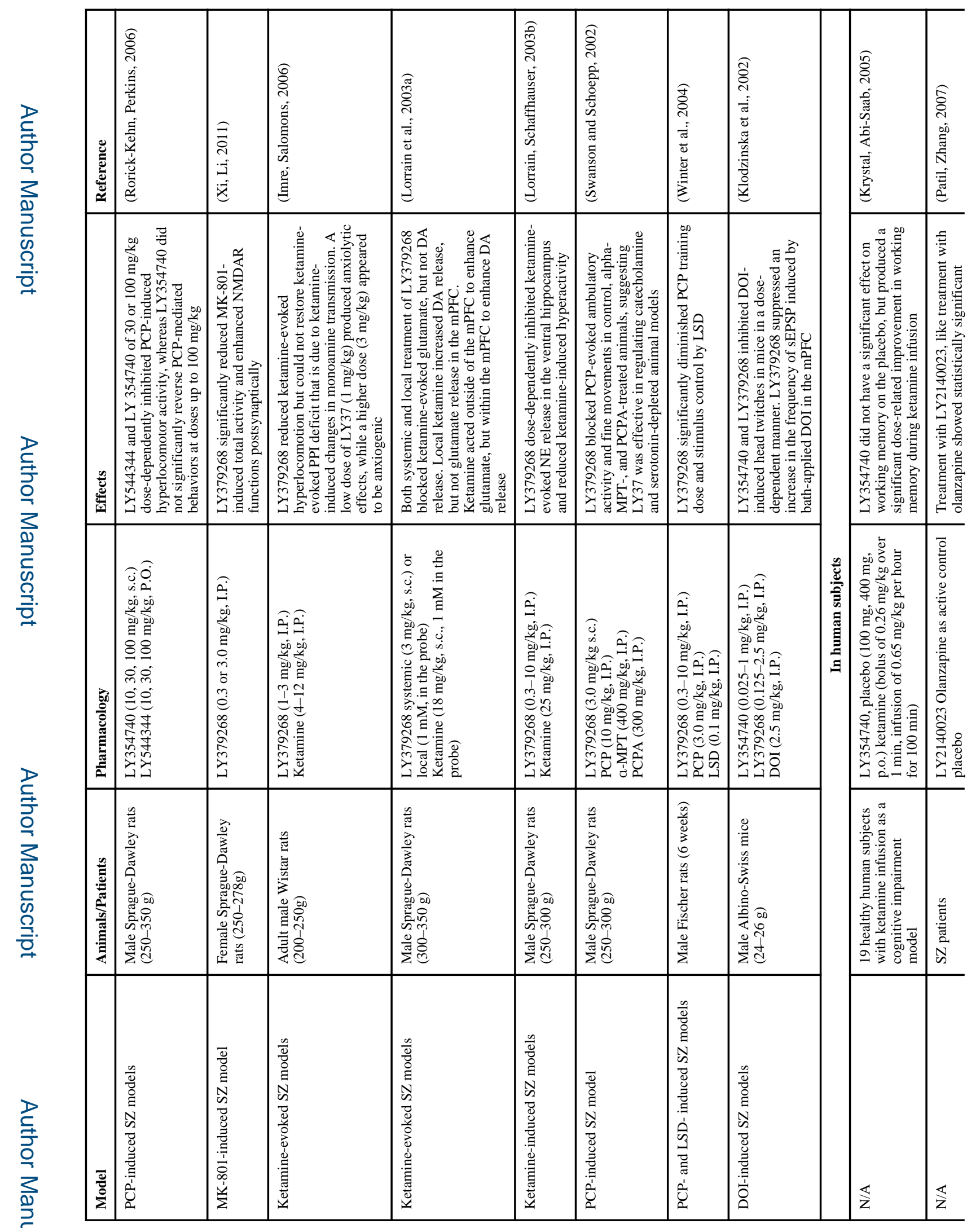

Prog Neuropsychopharmacol Biol Psychiatry. Author manuscript; available in PMC 2016 July 03. 


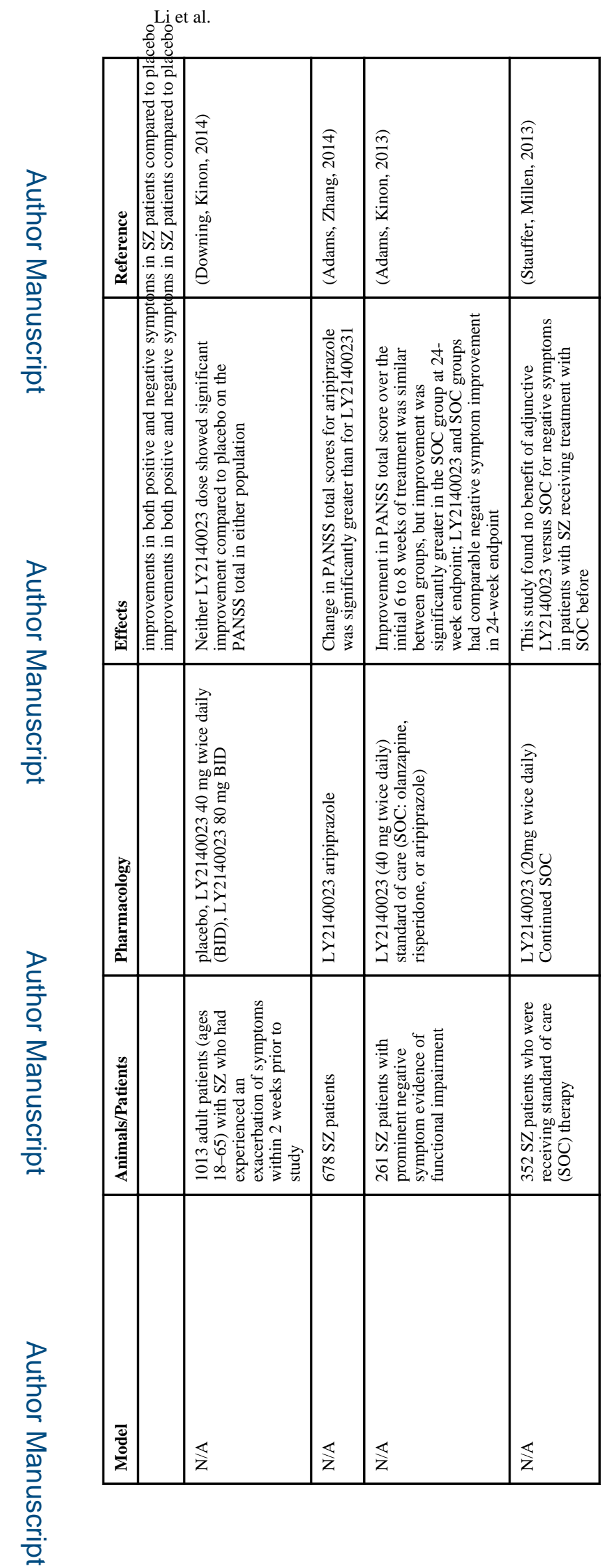

Page 29

Prog Neuropsychopharmacol Biol Psychiatry. Author manuscript; available in PMC 2016 July 03. 